\title{
Controlled Microfluidic Synthesis of Biological Stimuli-Responsive Polymer Nanoparticles
}

Yuhang Huang, Arman Moini Jazani, ${ }^{¥}$ Elliot P. Howell, Jung Kwon Oh, ${ }^{\ddagger}$ and Matthew G. Moffitt*

Department of Chemistry, University of Victoria, PO Box 1700 Stn CSC, Victoria BC V8W 2 Y2 Canada

${ }^{\ddagger}$ Department of Chemistry and Biochemistry, Concordia University, 7141 Sherbrooke St. West, Montreal, Quebec H4B 1R6, Canada

Supporting Information: GPC and ${ }^{1} \mathrm{H}$ NMR characterization of the copolymer; Plot of cwc determination; Sample image for microfluidic two-phase gas-liquid flow; Table of actual flow conditions; Work flow of PNP $R A$ compart determination; $R A_{\text {compart }}$ and $N_{\text {compart }}$ plotted vs. microfluidic flow rate; Stability test of quenched DualM PNPs by TEM and DLSand resulting tabulated data; Additional TEM images showing evolution of LVs from discrete spherical to discrete cylindrical to highly interconnected cylindrical compartments; Plot of $R_{R A}$ vs. $d_{\mathrm{h}, \text { eff,i. }}$

Corresponding Author's E-mail Address: mmoffitt@uvic.ca

Corresponding Author's Telephone: (250) 721-7162

Corresponding Author's FAX: (250) 721-7147 


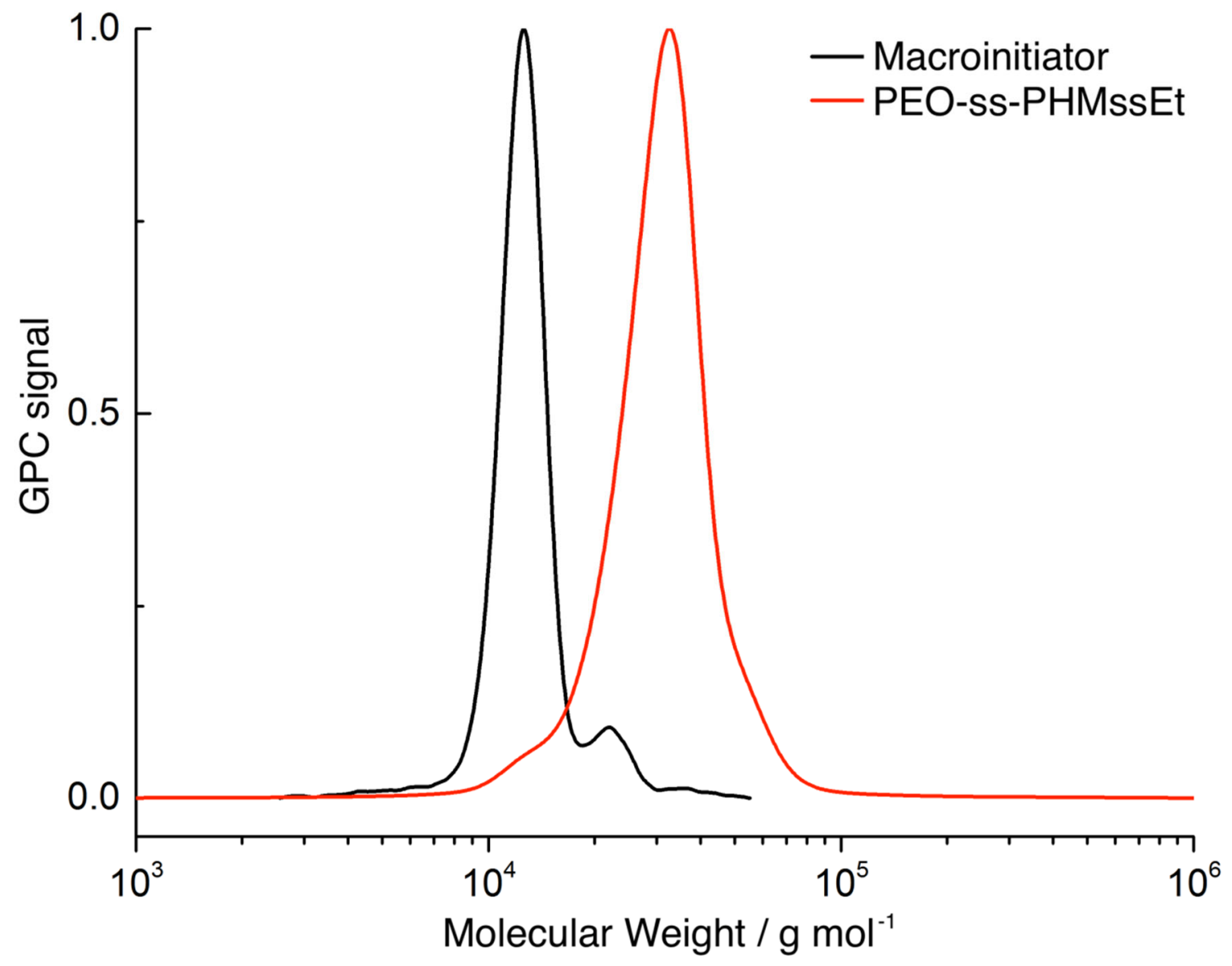

Figure S1. GPC chromatograms of PEO-ss-PHMssEt block copolymers and PEO-ss-Br macroinitiators in DMF solutions, which was further used to determine the molecular weight distribution $\left(M_{\mathrm{w}} / M_{\mathrm{n}}\right)$ of the resulting block copolymers. 

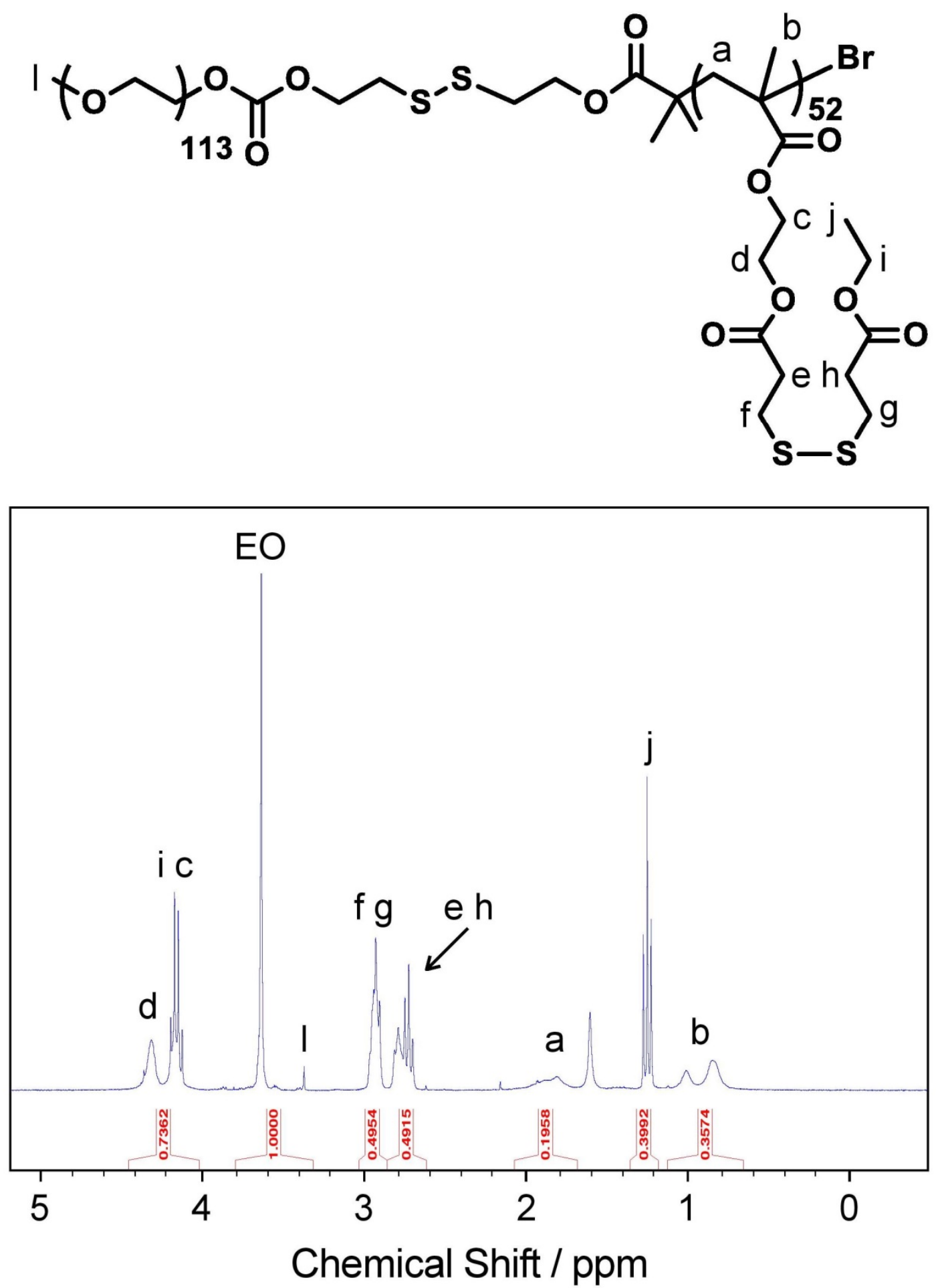

Figure S2. ${ }^{1} \mathrm{H}$ NMR spectrum of PEO-ss-PHMssEt copolymers in $\mathrm{CDCl}_{3}$ solution. The degree of polymerization (DP) was determined by the ratio between integration values of PEO and PHMssEt blocks. 


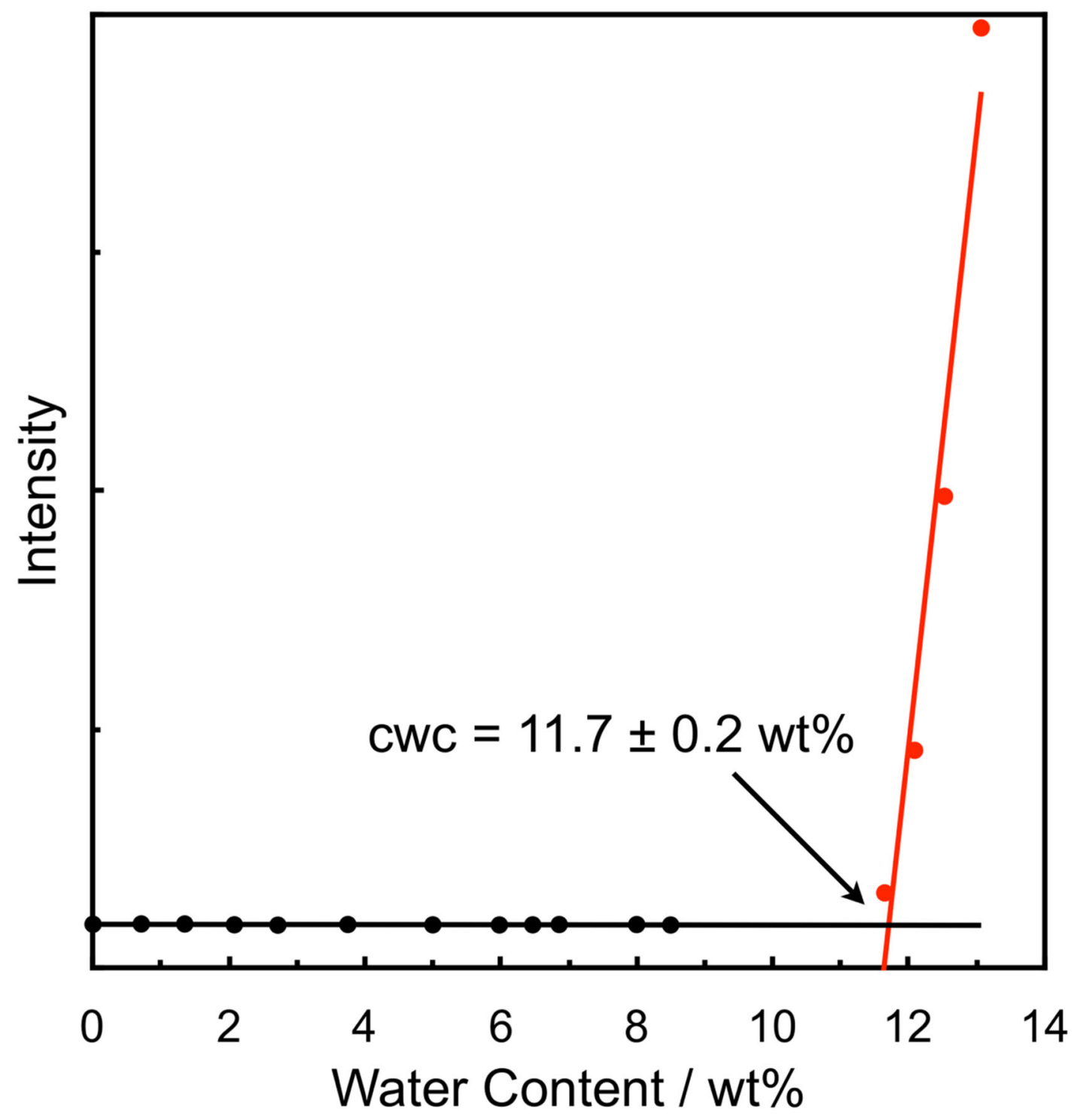

Figure S3. SLS was performed to determine the critical water concentration (cwc) of $0.33 \mathrm{wt} \%$ PEO-ss-PHMssEt in DMF solution, which was further used for the determination of the water content for on-chip DualM PNP preparations (cwc $+10 \mathrm{wt} \%)$. 


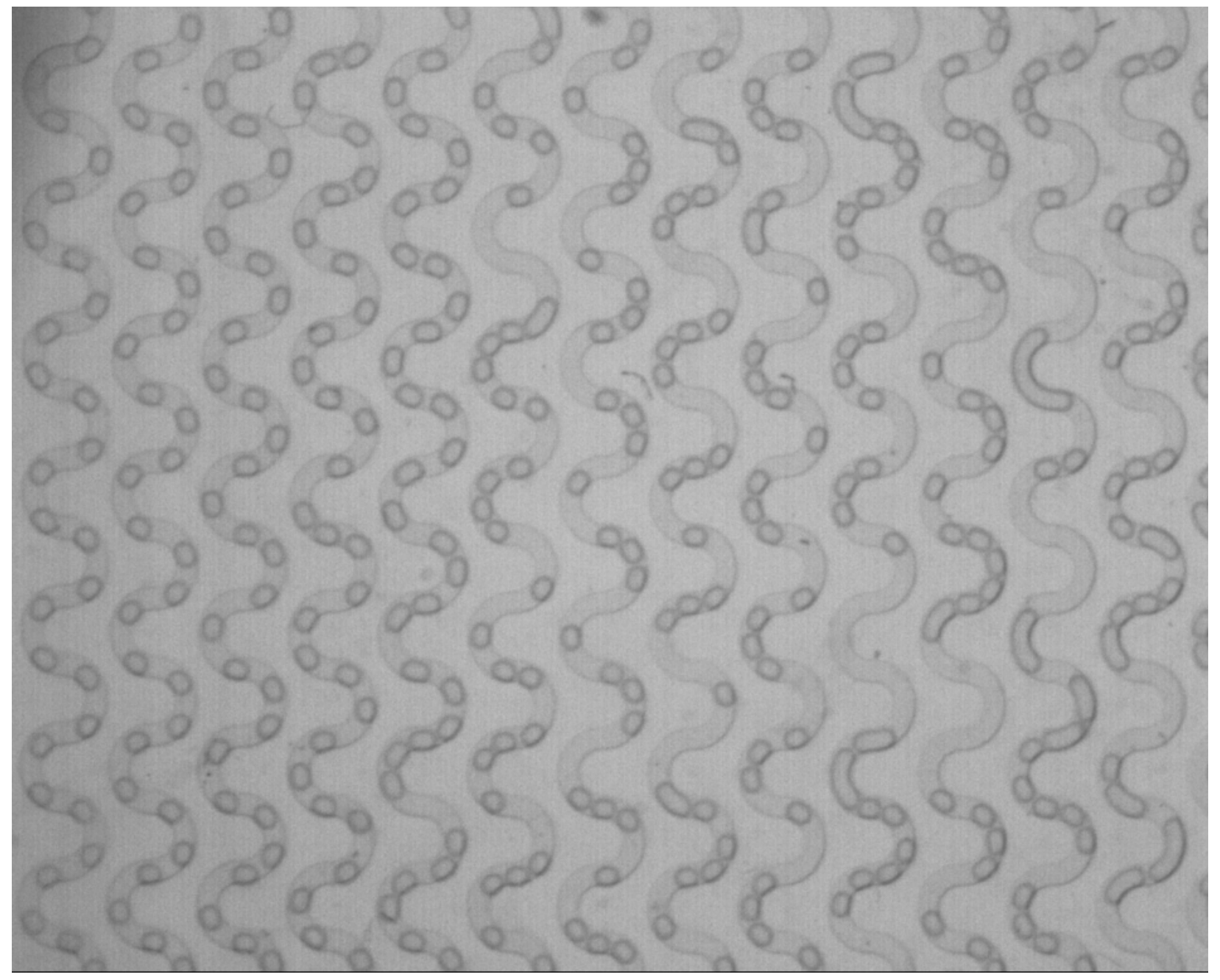

Figure S4. Typical optical microscope image of the stable two-phase segmented flow within the microfluidic reactor, in which plugs with black edges are Ar bubbles. 


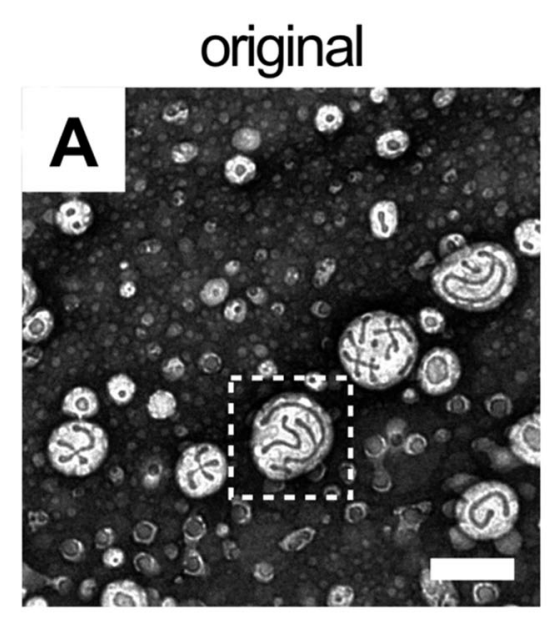

binarization

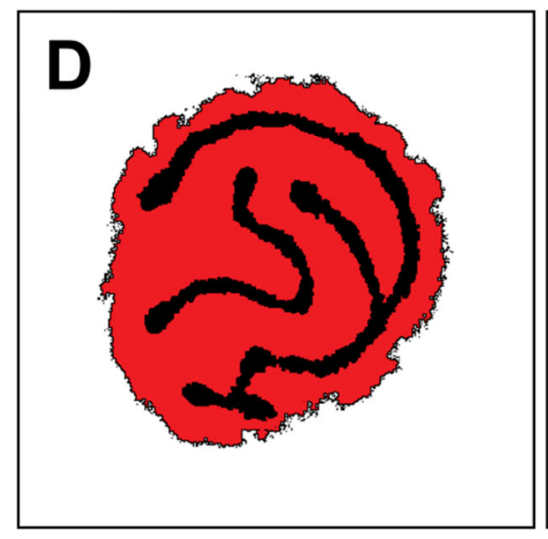

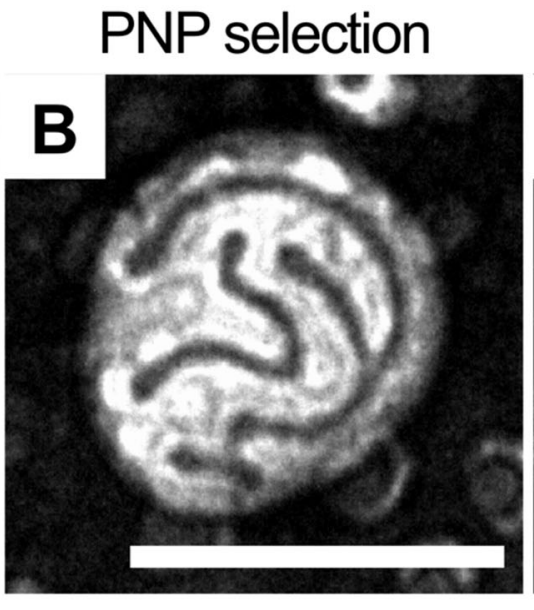

compartment area

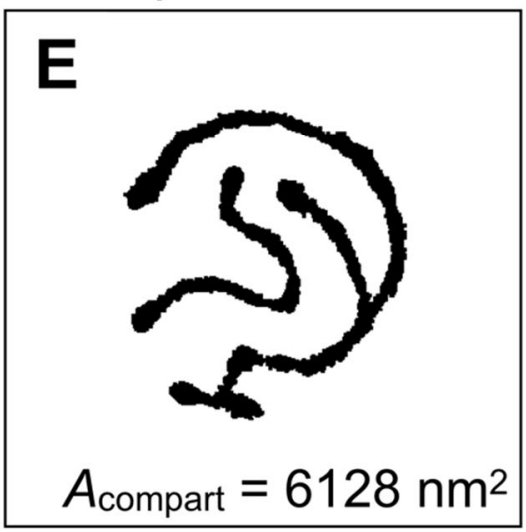

contrast adjustment

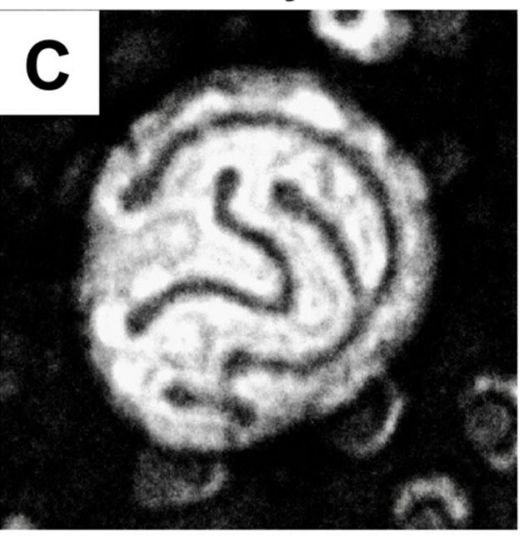

PNP area

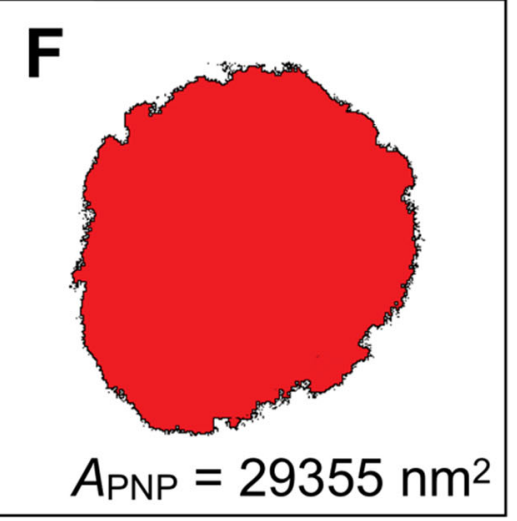

Figure S5. Work flow of PNP relative compartment area determination by TEM image analysis. First, (A-B) a single PNP containing inner compartments was cropped from the main image; (C) contrast was then adjusted, and (D) the boundaries of the PNP and its internal compartments were defined using the ImageJ binarization function. Next, the areas of the inner compartment (E, $A_{\text {compart }}$ ) and the PNP (F, $\left.A_{\mathrm{PNP}}\right)$ were determined using the measurement function in ImageJ. The value of $R A_{\text {compar }}$ for the individual PNP was calculated as $R A_{\text {compart }}(\%)=\frac{A_{\text {compart }}}{A_{\mathrm{PNP}}}=\frac{6128 \mathrm{~nm}^{2}}{29355 \mathrm{~nm}^{2}} \times 100=$ $20.88 \%$. Reported $R A_{\text {compart }}$ values represent averages calculated from $N \geqslant 50$ PNPs containing compartments selected from at least 3 images taken in different regions of the TEM grid. Scale bar is $200 \mathrm{~nm}$. 


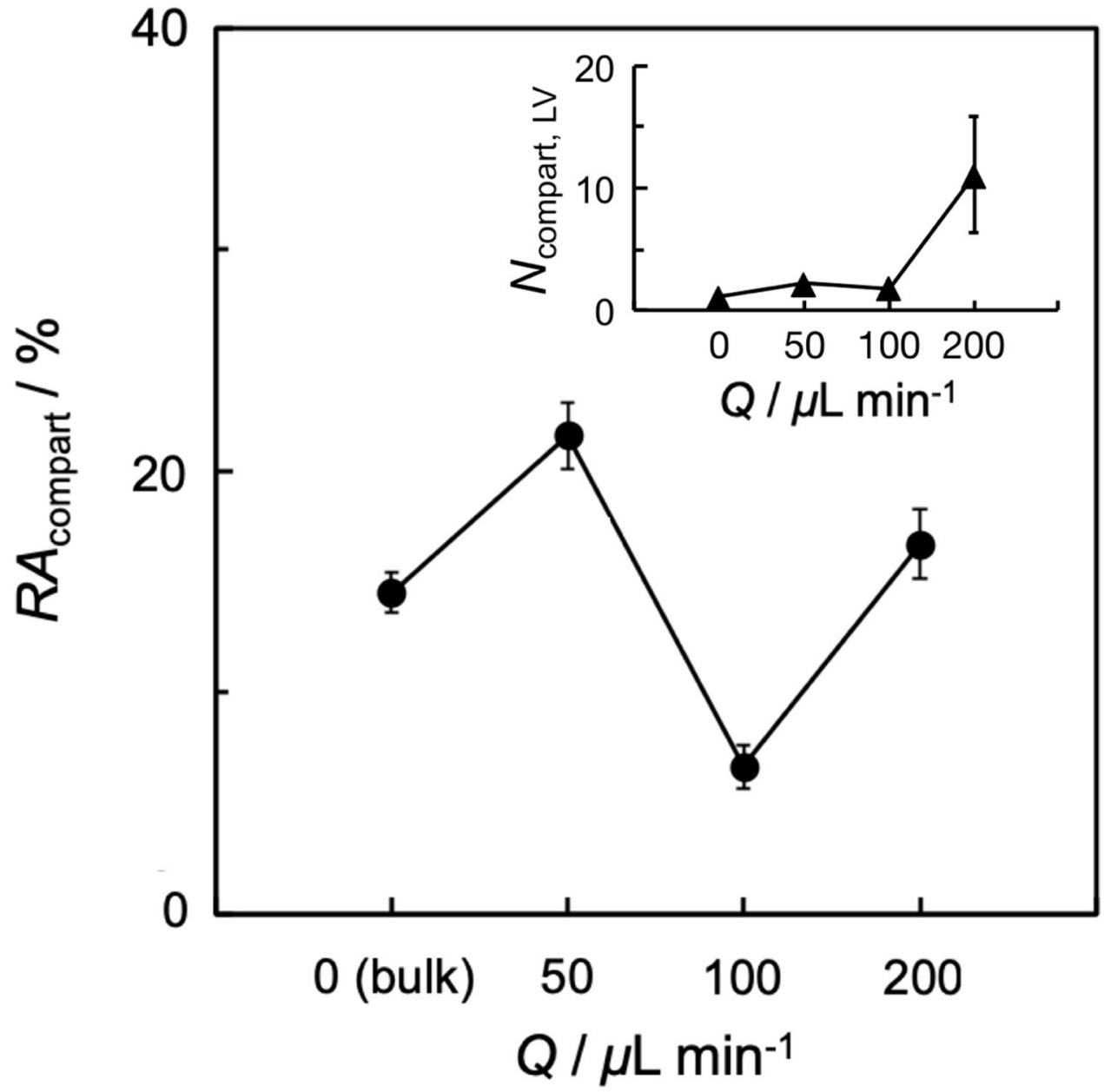

Figure S6. Effect of preparation method and microfluidic flow rate on the relative compartment area of DualM PNPs (main), and average number of compartments in LVs (inset). 

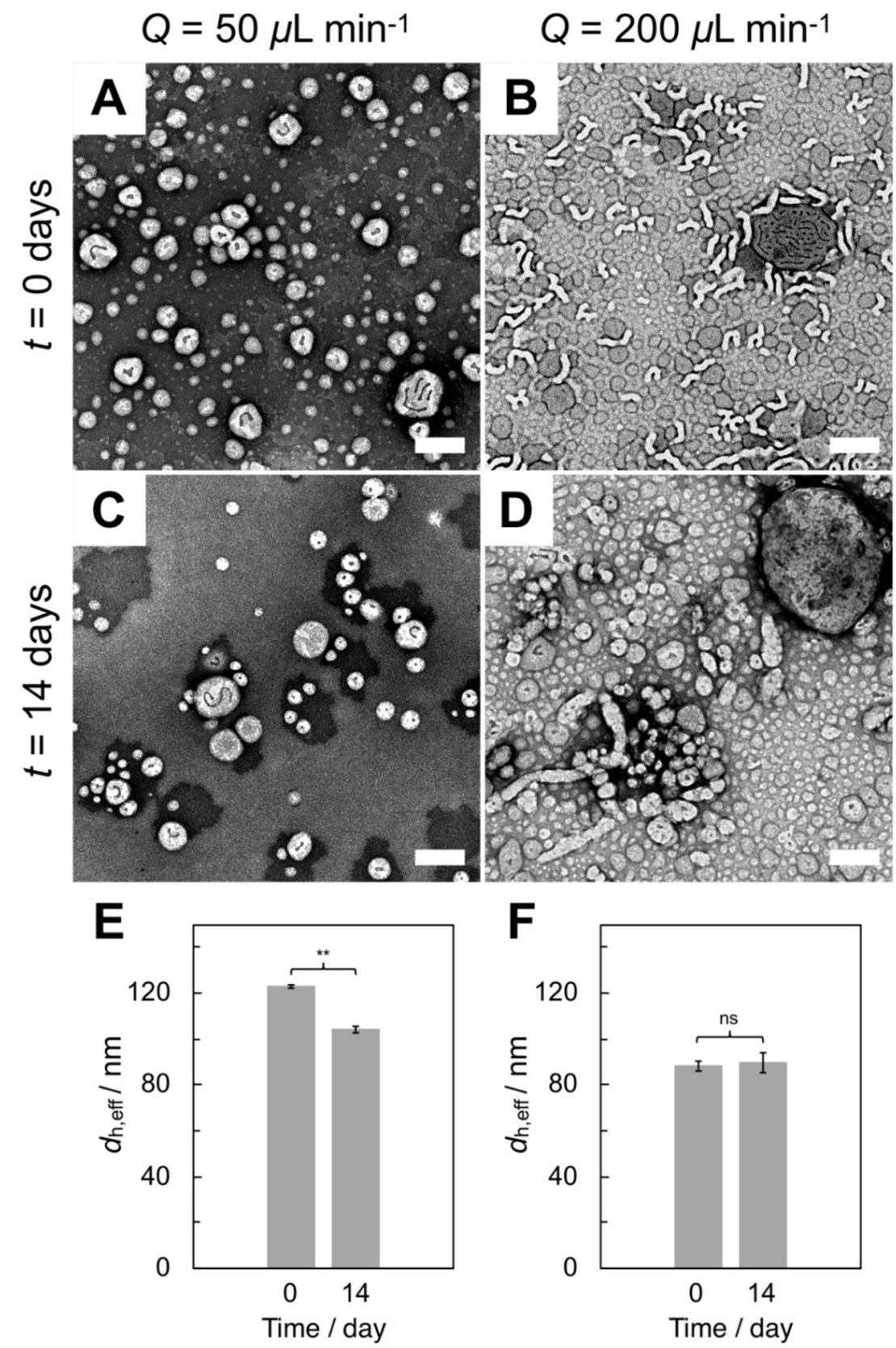

Figure S7. Stability test of quenched DualM PNPs manufactured at the $Q=50 \mu \mathrm{L} / \mathrm{min}$ and $Q=$ $200 \mu \mathrm{L} /$ min flow rates. TEM images (A-D) were taken immediately after dialysis ( $t=0$ days) and two weeks after dialysis ( $t=14$ days) for the two samples. Corresponding hydrodynamic effective diameters $\left(d_{\mathrm{h}, \text { eff }}, \mathrm{E}-\mathrm{F}\right)$ were also measured from DLS cumulant analysis for the comparison.

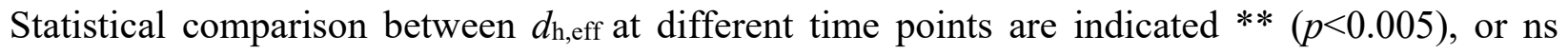
$(p>0.05)$. Experimental errors were calculated from three measurements for each sample. Scale bars are $200 \mathrm{~nm}$ in the TEM images. 


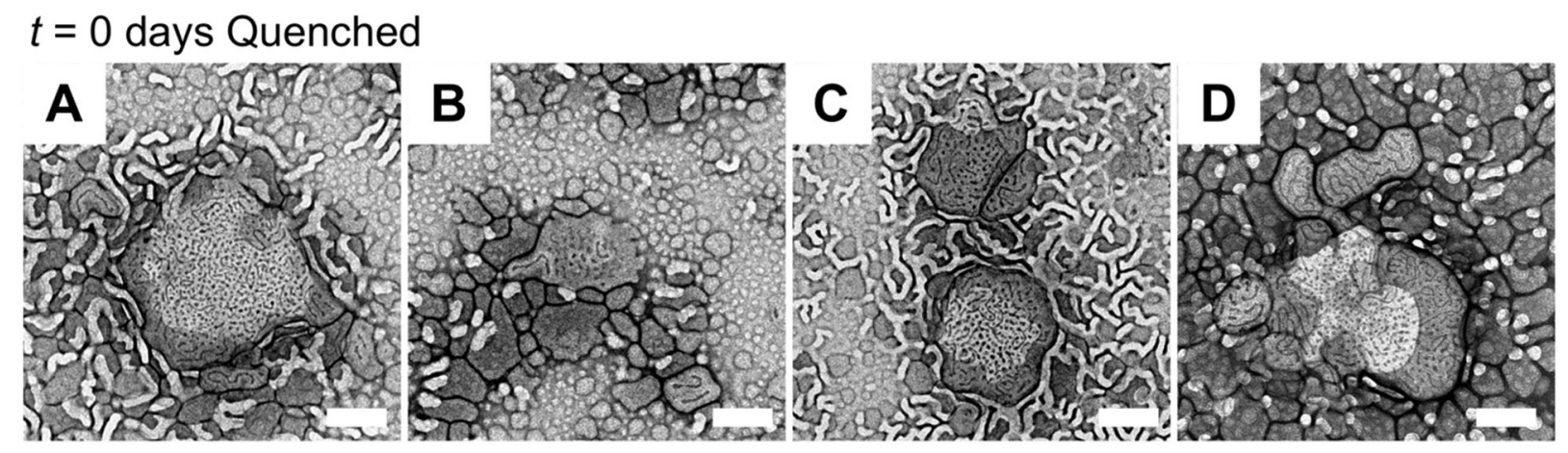

$t=0$ days Unquenched

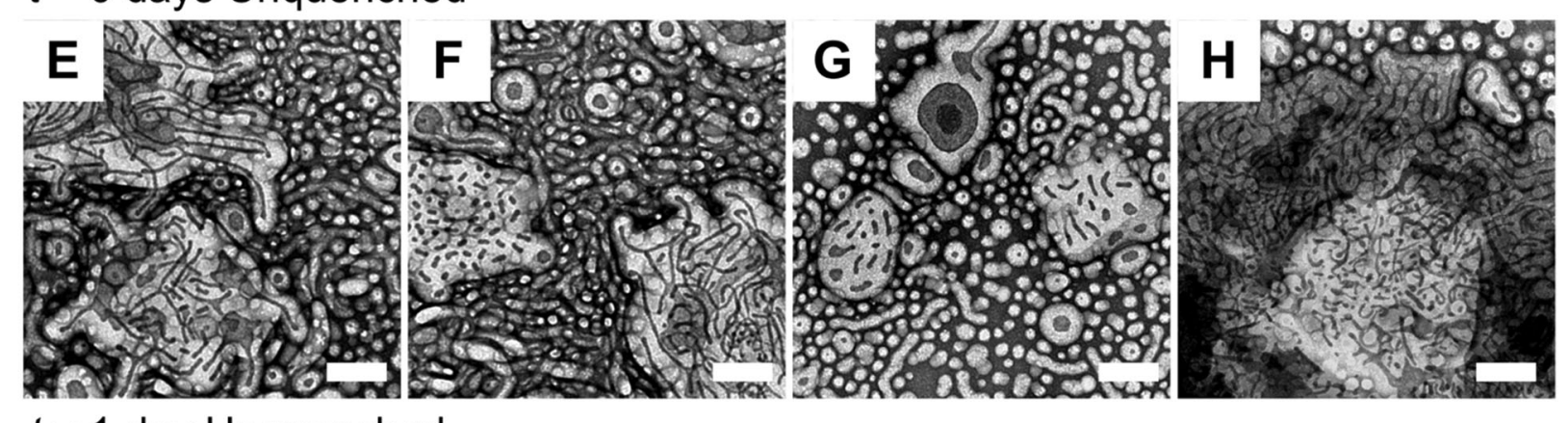

$t=1$ day Unquenched

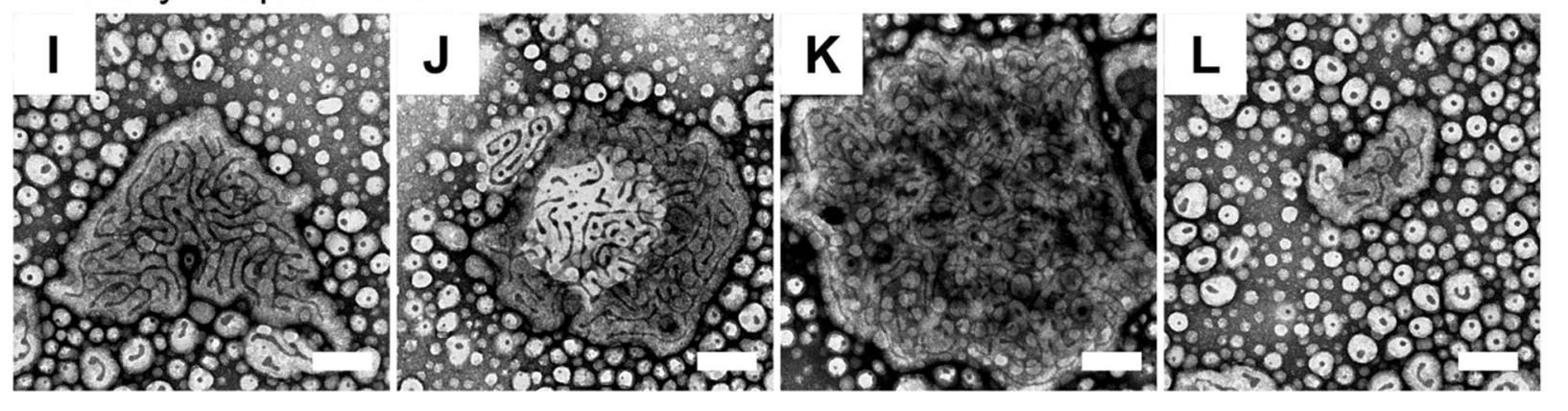

Figure S8. Additional TEM images shown progression of LVs from discrete spherical (A-D) to discrete cylindrical $(\mathrm{E}-\mathrm{H})$ to highly interconnected cylindrical compartments (I-L). Scale bars are $200 \mathrm{~nm}$ in the TEM images. 


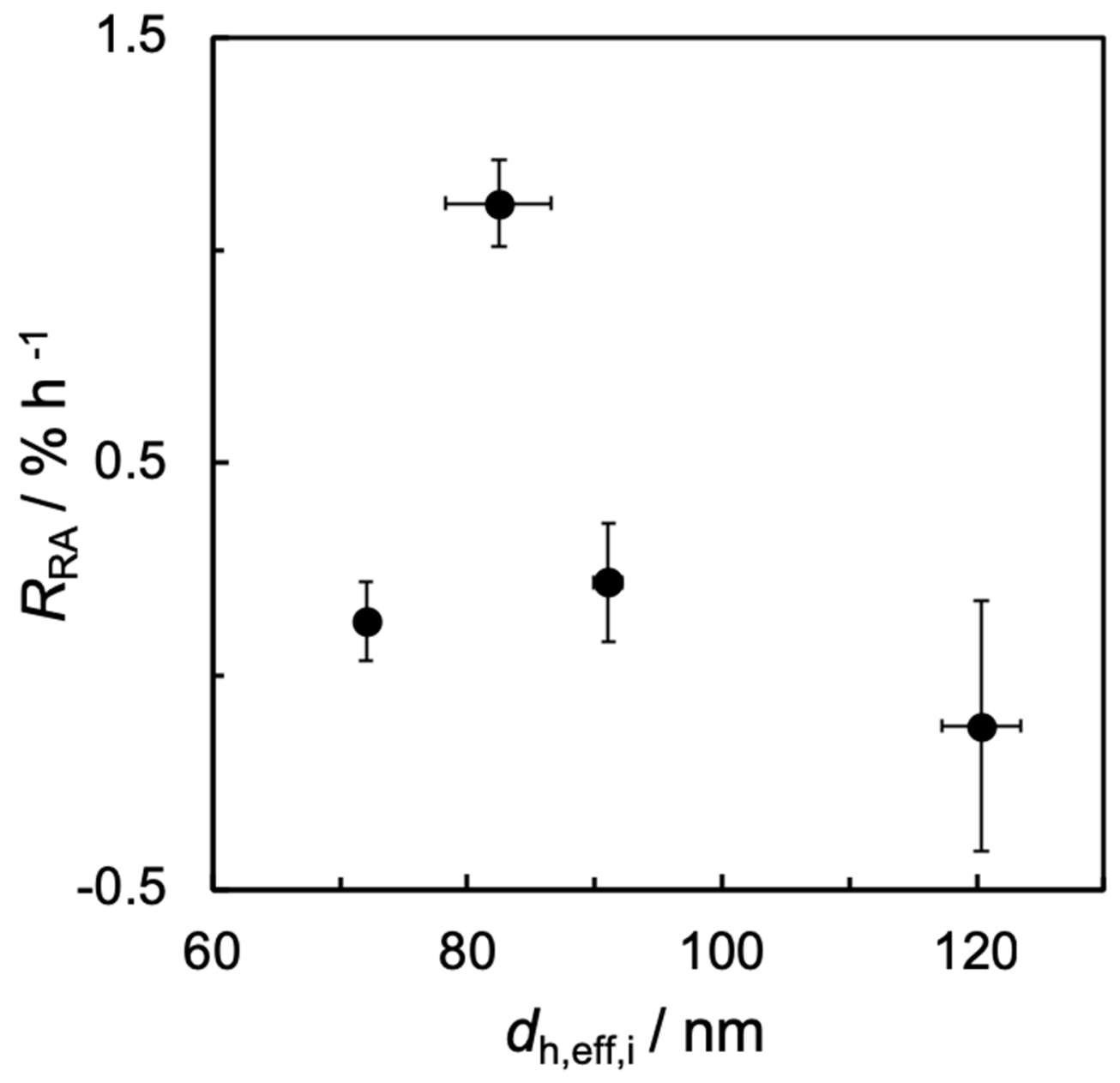

Figure S9. Average GSH-triggered growth rate of relative compartment area, $R_{R A}$ vs. initial effective hydrodynamic diameter, $d_{\mathrm{h}, \text { eff,i. }}$ Unlike the linear plot of negative slope for $R_{R A}$ vs. $R A_{\text {compart,i }}$ (Figure $11 \mathrm{~B})$, no obvious trend is found in the above plot. 
Table S1. Actual Flow Rates of Various Preparations of PEO-ss-PHMssEt PNPs within the Two-Phase Segmented Microfluidic Reactor Described in the Main Text

\begin{tabular}{ccccc}
\hline Nominal flow rate & $\begin{array}{c}\boldsymbol{Q}_{\text {gas }} \\
(\mu \mathbf{L} / \mathbf{m i n})\end{array}$ & $\begin{array}{c}\boldsymbol{Q}_{\text {liq }}{ }^{a} \\
(\mu \mathbf{L} / \mathbf{m i n})\end{array}$ & $\boldsymbol{Q}_{\text {gas }} / \boldsymbol{Q}_{\text {liq }}$ & $\begin{array}{c}\boldsymbol{Q}_{\text {total }} \\
(\mu \mathbf{L} / \mathbf{m i n})\end{array}$ \\
\hline $50 \mu \mathrm{L} / \mathrm{min}$ & & & 1.00 & 50 \\
Prep \#1 & 25 & 25 & 1.08 & 52 \\
Prep \#2 & 27 & 25 & 0.96 & 49 \\
Prep \#3 & 24 & 25 & & 101 \\
$100 \mu \mathrm{L} / \mathrm{min}$ & 51 & & 1.02 & 102 \\
Prep \#1 & 52 & 50 & 1.04 & 105 \\
Prep \#2 & 50 & 1.10 & \\
Prep \#3 & 55 & 50 & & 188 \\
$200 \mu \mathrm{L} /$ min & 88 & 100 & 0.88 & 193 \\
Prep \#1 & 93 & 100 & 0.93 & 214 \\
Prep \#2 & 114 & 100 & 1.14 & \\
Prep \#3 & & & & \\
\hline
\end{tabular}

${ }^{a}$ The liquid flow rate was assumed to be the sum of three flow-rate readings shown on the syringe pumps. 
Table S2. Time-Dependent Morphologies, ${ }^{a}$ Mean Dimensions, ${ }^{b}$ and Number Percentages for Quenched DualM PNPs Manufactured On-Chip at $Q=50 \mu \mathrm{L} / \mathrm{min}$ and $Q=200 \mu \mathrm{L} / \mathrm{min}$

\begin{tabular}{|c|c|c|c|c|c|}
\hline \multirow{2}{*}{$\begin{array}{c}Q \\
(\mu \mathrm{L} / \mathrm{min})\end{array}$} & \multirow[b]{2}{*}{ Morphology } & \multicolumn{2}{|c|}{$t=0$ days } & \multicolumn{2}{|c|}{$t=14$ days } \\
\hline & & $\begin{array}{c}\text { Dimension } \\
\text { / nm }\end{array}$ & $\begin{array}{c}\text { Number } \\
\text { Percentage / \% }\end{array}$ & $\begin{array}{l}\text { Dimension } \\
\text { / nm }\end{array}$ & $\begin{array}{c}\text { Number } \\
\text { Percentage / \% }\end{array}$ \\
\hline \multirow{3}{*}{50} & $\mathrm{~S}$ & $62 \pm 4$ & $77 \pm 2$ & $63 \pm 6$ & $65 \pm 5$ \\
\hline & SV & $71 \pm 3$ & $14.1 \pm 0.6$ & $69 \pm 4$ & $22 \pm 3$ \\
\hline & LV & $143 \pm 2$ & $9 \pm 3$ & $120 \pm 27$ & $13 \pm 7$ \\
\hline \multirow{4}{*}{200} & $\mathrm{~S}$ & $49 \pm 2$ & $61 \pm 5$ & $47 \pm 2$ & $60 \pm 4$ \\
\hline & SV & $67 \pm 4$ & $1.4 \pm 0.2$ & $61 \pm 3$ & $8 \pm 2$ \\
\hline & LV & $249 \pm 36$ & $4.2 \pm 0.5$ & $231 \pm 18$ & $7.1 \pm 0.9$ \\
\hline & $\mathrm{C}$ & $34 \pm 2$ & $35 \pm 4$ & $40 \pm 4$ & $25 \pm 4$ \\
\hline \multicolumn{6}{|c|}{$\begin{array}{l}{ }^{a} \text { Morphologies are indicated as S (spheres), SV (small vesicles), LV (large vesicles), or } \\
\text { (cylinders). }{ }^{b} \text { Dimensions refer to sphere and small vesicle diameters and cylinder width } \\
\text { determined from TEM images. For non-spherical large vesicles, dimensions refer to the longes } \\
\text { measurable internal distance. Standard errors are reported to represent the uncertainty of mea }\end{array}$} \\
\hline
\end{tabular}

